\title{
Cultura, território e turismo
}

\author{
Marina Evaristo Wenceslau \\ Universidade Estadual de Mato Grosso do Sul
}

Recebido: 19/11/2016 Versão revisada (entregue): 06/02/2018 Aprovado: 06/03/2018

\begin{abstract}
Resumo
As comunidades indígenas localizadas no município de Dourados, estado de Mato Grosso do Sul, são núcleos de atratividade cuja dinâmica histórica pode propiciar, por meio da cultura, uma identidade própria, mantendo em alguns casos sua alteridade através da língua materna, de seus mitos e ritos. O objetivo deste artigo é apresentar o processo cultural e a identidade indígena, baseado no tronco linguístico Guarani- Kayowá, Nandeva e Aruak-Terena, desenvolvendo, para isso, uma análise a respeito dessa representatividade, demonstrada por meio da produção alimentar, cultural e do modo de vida. Os procedimentos metodológicos adotados foram baseados na história oral de vida, com três perguntas de corte, conforme orientação de Mehine, em análise da sociedade Kayowá, dos seus produtos na contextualização prática, e da própria experiência indígena, através da cooperativa de artesãos criada pelos Guarani e Terena-Guateka, em seus territórios culturais.
\end{abstract}

Palavras-chave | comunidades indígenas; cultura; Mato Grosso do Sul; território; turismo.

Código JEL | J15; N96; Z10.

\section{CULTURE, TERRITORY AND TOURISM}

\begin{abstract}
The indigenous communities, located in the municipality Dourados (Mato Grosso do Sul-Brazil), are centers of attractiveness whose historical dynamics can provide, through culture, a proper identity. They maintain in some cases their alterity through the mother tongue, their Myths and rites. Thus, the objective of this article is to present the cultural process and indigenous identity, based on the Guarani- Kayowá, Nandeva and Aruak-Terena linguistic trunk, developing, for this purpose, an analysis about this representativeness, demonstrated through food, cultural and lifestyle. The methodological procedures were based on the analysis of the products in the practical contextualization, through the indigenous experience itself. It is possible through the cooperative of artisans created by the Guarani and Terena, represented by these societies, in their cultural territories.
\end{abstract}

Keywords | Culture; indigenous communities; Mato Grosso do Sul; territory; turism.

JEL-Code | J15; N96; Z10. 


\section{CULTURA, TERRITORIO Y TURISMO}

\section{Resumen}

Las comunidades indígenas, ubicadas en el municipio de Dourados, estado de Mato Grosso do Sul, son atractivos núcleos cuya dinámica histórica puede proporcionar, a través de la cultura, una identidad propia, manteniendo en algunos casos su alteridad por medio de la lengua materna de su mitos y ritos. El objetivo de este artículo es presentar el proceso cultural y la identidad indígena, basada en la rama lingüística Guaraní Kayowá, naandeva y Aruak- Terena, desarrollando, para ello, un análisis con respecto a esta representación, demostrada por medio de la producción de alimentos, la cultura y el modo de vida. Los procedimientos metodológicos adoptados se basan en la historia oral de vida, con tres preguntas de corte, conforme los presupuestos de Mehine, en el análisis de la sociedad Kayowá, de sus productos en el contexto práctico, y de la propia experiencia indígena, a través de la cooperativa de artesanos creada por los Guarani y TerenaGuateka, en sus territorios culturales.

Palabras-clave | comunidades indígenas; cultura; Mato Grosso do Sul; territorio; turismo.

Código JEL | J15; N96; Z10.

\section{Introdução}

As comunidades indígenas Guarani e Terena estão localizadas, hoje, no município de Dourados, estado de Mato Grosso do Sul, Brasil, e são núcleos de atratividade cuja dinâmica histórica pode propiciar, por meio da sua cultura, uma identidade própria e a sua alteridade, mantidas através da manutenção da língua materna na grande maioria das famílias na Terra Indígena de Dourados (TID), de seus mitos e ritos praticados principalmente entre as famílias Guarani. No mesmo espaço territorial, os Terena, do grupo linguístico Aruak, tem como língua materna o português e somente uma família é falante da língua terena. Assim, o objetivo deste artigo é apresentar o processo cultural indígena, baseado no tronco linguístico Guarani-Kayowá, Nandeva e Aruak-Terena, tendo como método a análise dessa representatividade, demonstrado também pela produção artesanal, com destaque para sua identidade. Assim, para obtenção das informações, a História Oral de Vida, determinada por MEHINE, se fez presente através de entrevistas anteriormente realizadas com famílias que praticam as rezas, danças e produzem artesanato.

Tanto na identidade e na língua materna como na cultura, os Kayowá são vistos como aqueles que mantém a base da sua identificação alicerçada neste tripé e esse fato desperta o interesse dos turistas que passam pela cidade, pois os indígenas circulam diariamente pela área urbana, ora vendendo produtos alimentícios, ora artesanato.

Os procedimentos metodológicos foram baseados também em análise dos produtos artesanais, na contextualização por meio da própria experiência e prática nos usos e 
costumes indígenas, através da cooperativa de artesanato criada pelos Guarani e pelos Aruak representados na TID, nos territórios culturais da comunidade indígena. Os resultados obtidos desvelam o agrupamento dos produtos que qualificam o desenvolvimento cultural através da identidade e da alteridade em sua preservação de atividades fundamentais, elevando as expectativas da própria comunidade.

O método desenvolvido foi a História Oral de Vida, baseado na forma de ação orientada tanto por VANCINA, como por MEHINE, para obter informações da família, da comunidade e da liderança. As entrevistas tiveram três perguntas de corte, como: 1 - Dança, reza, alimentação, organização familiar; 2 - artesanato e sua produção; e 3 - qual o papel da comunidade e sua importância. A estrutura do artigo está dividida em: Cultura e Identidade; Território: Contexto da Comunidade Indígena Guarani-Kayowá e Ñandeva e O Processo Histórico desta Cultura Indígena. Tivemos o cuidado de apresentar esta divisão para que ficasse claro como vivem, o que pensam e como se dá a ação dentro da comunidade.

\section{Cultura e Identidade}

O território da TID faz parte não do sistema de identificação dos Guarani, mas do sustentáculo, do lugar onde se realiza esta sociedade, onde a vida se complementa com os anseios, o devir, os mitos e os ritos. Enquanto os Terenas passaram por transformação ainda maior devido a mudança do território, vindos da região de Aquidauana/MS para a TID, que na época não era território original, e, no entanto, o Órgão Tutelar entendeu que o seu deslocamento iria favorecer os Guarani, pois os Terena teriam a obrigação de ensiná-los a plantar e isso ocorreu através da ação do SPI (Serviço de proteção ao Índio). Destacamos que estas mudanças ocorreram desde o período colonial, pois o indígena perde sua terra paulatinamente e enfrenta mudanças internas para seu povo que está acostumado a viver livremente, caçando e pescando, plantando para subsistência e perambulando. No caso da TID, as mudanças são radicais, década a década, começando pela perda das terras e, depois, da mata; hoje, com o aumento considerável da população, a falta de condições de sobrevivência através da produção de subsistência.

Salientamos que, neste momento, a terra mantém, para os Guarani, um sentido de sagrado, cultural, vida, sendo que ritos ainda são manifestados no dia a dia, na necessidade de preservar a terra para seus filhos, netos, bisnetos, e a considerando também o local onde descansam seus mortos.

Apesar de todas as dificuldades já citadas, os indígenas não reconhecem as fronteiras territoriais, mas observam que, para sobreviver, é necessário entrar no mercado de trabalho sem, contudo, deixar de lado alguns elementos básicos de sua cultura. As 
fronteiras não se limitam apenas às demarcações territoriais, mas também ao sentido de vida, as visitas a seus parentes, a luta pela sobrevivência e outros elementos.

A língua materna para os Guarani, segundo as lideranças familiares e o capitão, é sua grande defesa, sua forma de preservação, de proteção contra aqueles que invadem suas vidas e famílias, acabando por invadir suas próprias casas, chegando muitas vezes a desestruturar a organização familiar. Merecendo destaque, mais uma vez, a terra, que é o centro de sua sustentação cultural, podendo estar dividida em três regiões distintas:

\section{Fig. 1: Mapa estrutural dos Guarani}

Fonte: Dissertação de Mestrado-USP, de Marina Evaristo Wenceslau, 1986.

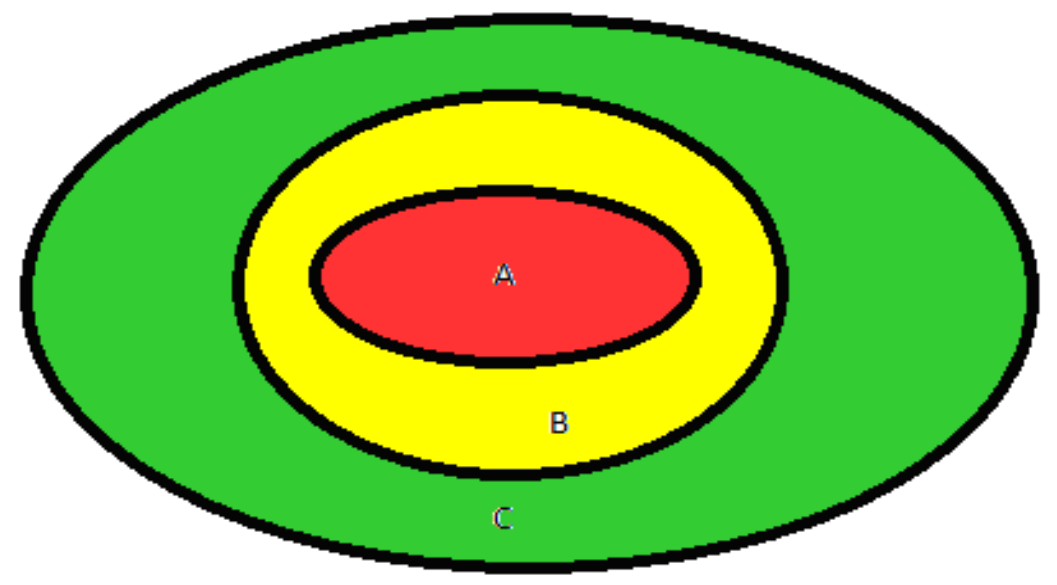

Para os Guarani a família é o alicerce de vida e se organiza da seguinte forma (WENCESLAU: 1994, 86):

A) da casa e terreiro - para uso da própria família, tanto para armazenamento dos alimentos como para algumas pequenas atividades;

B) do plantio - atividade feita apenas pelas mulheres na antiguidade, hoje o homem também o faz, e;

C) da perambulação - espaço do território destinado a todos para a caça, a pesca e as atividades do caminhar para espantar os males.

Enquanto isso, os Terena lutam para entrar no mercado de trabalho e de produção na área urbana da cidade de Dourados. Possuem objetivos e sentido de vida distantes da dos Guarani.Destaca-se aqui que, apesar da importância, a maioria do território indígena, da TID, não oferece condições da concretização desta tradição.

No caso dos Guarani, a análise deste território caracteriza-se por uma questão que o reconheça como um espaço onde as emoções são afloradas e a história vivida é perpetuada, o que se aplica devidamente ao exemplo das comunidades indígenas distribuídas por terras em todo o território brasileiro. 
Portanto, a questão que envolve a TID denota a tomada de consciência dos Guarani, dentro de seu território, ao se realizar a vida, ao organizar, ao respeito do saber dos mais velhos, ao apreender a crença e as festas através do saber dos mais velhos e, principalmente, os espaços utilizados para cada atividade.

\section{Fig. 2: Limite da TID e a área urbana da cidade de Dourados}

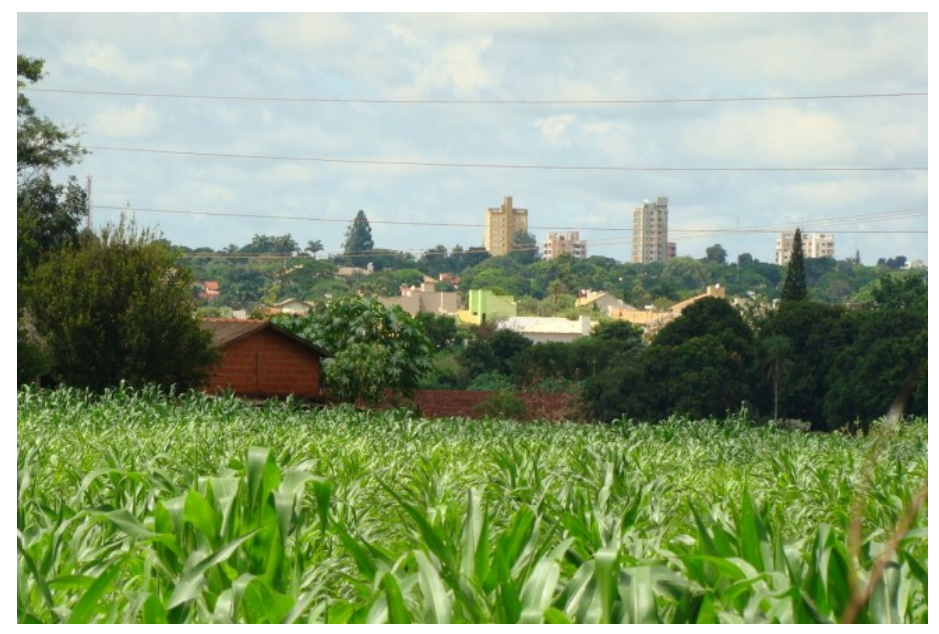

Fonte: Foto de Marina Evaristo Wenceslau, 1998

A proximidade da TID com a área urbana da cidade traz um confronto visível da cultura, dos usos e dos costumes tanto para os Guarani quanto para os Terena.

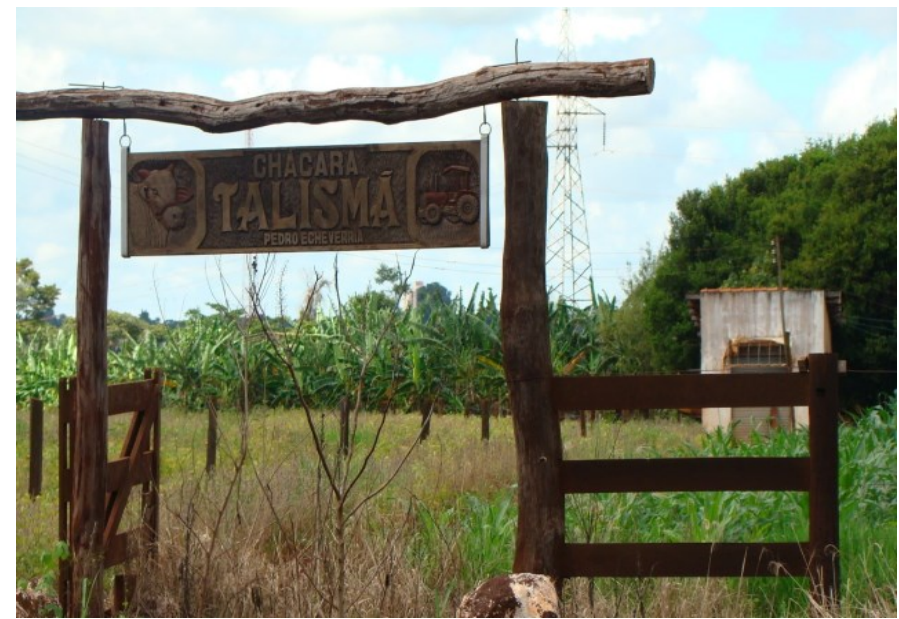

Figura 3: Limite da TID e uma das chácaras na divisa.

Fonte: Foto de Marina Evaristo Wenceslau, 1998 
Como hoje o espaço é exíguo, sem condições muitas vezes de plantio, torna-se necessária a changa, que é o trabalhar para outra pessoa, passando a receber um salário ou diária. Ora o trabalho é prestado para os fazendeiros circunvizinhos da aldeia, ora para o plantio da cana, ora prestam serviço na cidade como: mecânicos, domésticas ou vendem produtos como mandioca, milho, abóbora ou, algumas vezes, para o próprio patrício.

\section{Fig. 4: Rodovia que corta a TID, ligando o município de Dourados a Itaporã.}

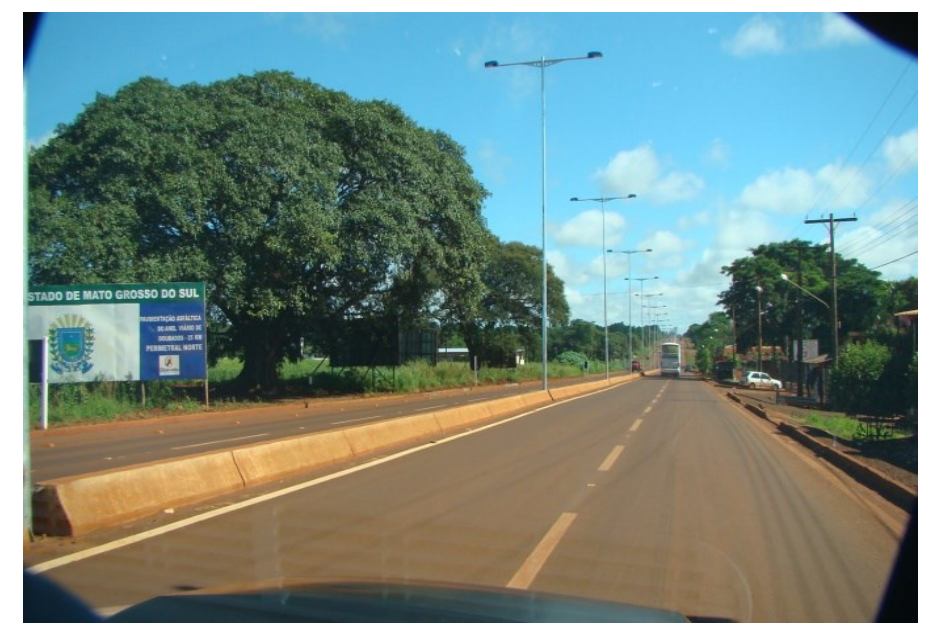

Fonte: Foto de Marina Evaristo Wenceslau, 1998

Como se todas as dificuldades presentes tivessem condições de serem resolvidas pelos próprios indígenas, uma Estrada Estadual corta a TID, dividindo-a em duas partes. Destacamos que a comunidade não foi até hoje ressarcida pela perda de espaço territorial. Esta rodovia é considerada como Rodovia da Morte, porque mais de dez indígenas já foram mortos, considerando o excesso de velocidade, sem considerar os atropelamentos diários e, também, o transtorno diário para quem vive às margens desta mesma rodovia. Há pouco tempo foram construídas lombadas para que as pessoas que usam esta rodovia diminuam a velocidade ao transitar por ela. É necessário informar também que a rodovia serve de caminho para os indígenas irem e virem a cidade de Dourados com suas carroças, bicicletas, motos e \ou carros, mas esse caminho na maioria das vezes é feito a pé.

E como não há espaço suficiente para o plantio, espaço de mata para perambular, estes elementos tornam-se apenas uma lembrança do passado. Descaracterizando os três elementos do espaço que existe na cultura e não de fato.

A história de contato dos Guarani com a sociedade abrangente justifica, legitima o antagonismo do não índio, limitando, ao máximo, a realização de casamentos interétnicos. A referência ao purismo racial justifica-se por este antagonismo com relação aos "civilizados"; e, ao mesmo tempo, garante sua continuidade. 
As terras da TID estão tituladas de acordo com o Decreto n ${ }^{\circ}$. 404, de 03/09/1917, e registradas às folhas do livro n ${ }^{\circ}$. 23, em 14/02/1965; no Cartório de Registro de Imóveis de Campo Grande, em 26/11/1965, conforme despacho do Secretário de Agricultura do Estado de Mato Grosso, de 23/11/1965 (MONTEIRO, 2003), com um espaço territorial de 3.600 ha. A referida área somente teve seu Título Definitivo de Propriedade expedido em 28/10/1985 e seu registro em 14/12/1985. Esta área foi, inicialmente, reservada aos índios da etnia Kaiowá, que já ocupavam o local e suas imediações.

Está localizada, no município de Dourados, possuindo parte de seu território, também, a vizinha cidade de Itaporã. Com o passar do tempo, o espaço total foi dividido em duas aldeias, a Aldeia Bororó e a Jaguapiru. Destaca-se que a aldeia Bororó possui uma população fundamentalmente formada pelos Guarani. No entanto, Jaguapiru é basicamente povoada pelos Terena e mestiços, tanto com não índio como com os Guarani.

Para os Guarani, o Tekohá é importante na formação da identidade, mas o território não é determinante, devido às frequentes migrações. Direitos que as comunidades indígenas possuem, o que é extremamente importante, porque para eles o direito à terra é sagrado.

Quanto aos Terena, sabe-se que vieram para o território trazidos pelos funcionários do antigo Serviço de Proteção ao Índio (Relatório do SPI, 1955), em 2 famílias, basicamente para ensinar os Guarani a plantar. Como se isso já não acontecesse entre eles.

A Constituição Federal do Brasil de 1988 reconhece a importância cultural e indentitária, e ressalta-a por meio dos artigos 215 e 216

Art. 215. O Estado garantirá a todos o pleno exercício dos direitos culturais e acesso às fontes da cultura nacional, e apoiará e incentivará a valorização e a difusão das manifestações culturais (...)

Art. 216. Constitui patrimônio cultural brasileiro os bens de natureza material e imaterial, tomados individualmente ou em conjunto, portadores de referência à identidade, à ação, à memória dos diferentes grupos formadores da sociedade brasileira.

Os núcleos indígenas devem ser tratados como patrimônio cultural de interesse da União, estados e municípios e, como tal, devem ser preservados de qualquer ação conflituosa, garantindo concomitantemente sua manutenção e integridade, uma vez que os territórios integram a formação da identidade nacional.

Dois aspectos importantes da legislação respaldam a condição do território tomado como base física. Sobre a questão indígena, tem-se o $\$ 2^{\circ}$ do art. 231 , ao acrescentar que: 
Art. 231. São reconhecidos aos índios sua organização social, costumes, línguas, crenças e tradições, e os direitos originários sobre as terras que tradicionalmente ocupam, competindo à União demarcá-las, proteger e fazer respeitar todos os seus bens.

$\int 2^{\circ}$ - As terras tradicionalmente ocupadas pelos índios destinam-se a sua posse permanente, cabendo-lhes o usufruto exclusivo das riquezas do solo, dos rios e dos lagos nelas existentes.

Atualmente a situação das comunidades indígenas no Brasil é diferenciada, caracterizando-se pela designação de uma herança cultural que confere o direito de ser, ter e pertencer aos seus territórios específicos e tradicionais. A discussão sobre a territorialidade envolve formas de uso do espaço e de seus recursos naturais, organização social e econômica, sistemas de valores de uso e simbologia, quando se aloca a questão da territorialidade como um fator vital que justifica a construção de sua identidade, porque a territorialização dos indígenas está ligada ao coletivo, na qual a identidade indígena está representada e estruturada culturalmente.

Frente a essa perspectiva dos territórios culturais, o presente artigo tem como objetivo principal discutir a representatividade cultural destes indígenas, bem como as possibilidades de fomento no território étnico identificado no município de Dourados. A metodologia utilizada para alcance dos objetivos já delineados foi baseada em análise teórica documental e na sua contextualização, por meio da experiência registrada em campo.

\section{Território: Contexto da Comunidade Indígena Guarani-Kayowá e Ñandeva}

A população indígena de Mato Grosso do Sul é hoje o segundo contingente populacional do Brasil, sendo superado apenas pelo estado do Amazonas. Nota-se que naquele estado (MS) há uma população indígena estimada em 50.000 índios aldeados e 5.000 desaldeados, além de possuir diversos grupos étnicos diferenciados, como os Kaiowás, Ñandevás, Terenas, Kadiwéus, Kinikinawas, Guatós, Atikums, Ofaiés e Cambas (em processo de reconhecimento como povo brasileiro). (FUNAI, 2010).

A TID, antes nomeada Posto Indígena "Francisco Horta Barbosa", está localizada na zona norte do município de Dourados. Distante $3,5 \mathrm{~km}$ do centro urbano de Dourados, mais precisamente, da Praça Antônio João, e também, a $8 \mathrm{~km}$ do município vizinho, Itaporã. A TID é cortada pela Rodovia MS-156, que liga Dourados a Itaporã, no sentido norte/sul. Segundo dados da Fundação Nacional 
de Saúde/FUNASA (2009), conta com uma população de aproximadamente 12.000 indígenas, distribuídos em 3.539 hectares. $\mathrm{Na}$ aldeia Bororó destaca-se a presença maciça do tronco linguístico Guarani, Kayowá e Ñandeva e na aldeia Jaguapirú, encontram-se a comunidade Terena, uma pequena população Ñandeva e Kayowá, além dos mestiços que se fazem presentes em ambas as aldeias.

Para entender as relações socioculturais entre os povos indígenas habitantes na TID, é necessário compreender cada grupo que está dividido em três setores distintos, sendo: o oeste ocupado pelos Kayowá, o centro pelos Ñandeva, o leste os Terena, e os mestiços em ambas as aldeias, conforme reconhecimento do território da TID durante as incursões para as entrevistas no local.

Os grupos existentes na TID se diferenciam em diversas dimensões culturais, tanto por sua origem como por sua representação, a partir da ocupação do próprio território no município de Dourados. Cada povo possui seus traços tradicionais e, ao mesmo tempo, diferentes fases de adaptação estimuladas pelo contexto socioeconômico e cultural do entorno.

De acordo com os apontamentos de Haesbaert (2001), “os povos indígenas Kayowá da TID vivem de certa forma desterritorializados, tanto no sentido social ligado às questões da miséria, da desnutrição, da falta de terra, aumento acelerado dos povos, do suicídio, como nos aspectos culturais relacionados às interferências dos não indígenas", ainda, como no aspecto religioso, com a introdução de dezenas de igrejas evangélicas na TID, na dança, com a expansão da música eletrônica, e na gastronomia com os hábitos e costumes do entorno.

A TID compreende uma complexa área de estudo, estimulando uma reflexão a respeito da formação histórica e geográfica, considerando os fatores que implicaram a massificação e a degradação local que provocam impactos negativos na natureza, nas culturas indígenas. Esses impactos são relacionados principalmente a retirada da madeira na década de 1.970, como consta nos processos de apresamento de caminhões de madeira da TID, a destruição da terra com o Projeto Nosso Índio um Cidadão, durante a administração de Pedro Pedrossian, e ao período de capitania de Ramão Machado quando tirava terras de um e doava a outros (1970), aumento populacional (segundo Censo da FUNAI e FUNASA), extermínio da mata nativa essencial para subsistência, indumentária, artefatos, entre outros e, ainda, a interferência da comunidade do entorno sobre as questões político-administrativas.

Nesse sentido, analisam-se, portanto, as modificações e interferências no modo de ser e viver Kayowá, estimulado principalmente em função dos aspectos econômicos gerados pelo modo de produção capitalista e na maioria das vezes com a anuência da FUNAI. Os efeitos gerados nas comunidades tradicionais são decisivos pela reconfiguração dos valores pessoais e comunitários, que possibilitam uma dependência de ações afirmativas e assistencialistas exógenas, principalmente promovidas pelas políticas públicas vigentes. 
Focando na análise deste trabalho para promover uma discussão sobre a produção material e imaterial dos Guarani da TID, acredita-se que será preciso compreender a essência da promoção da interculturalidade seja pelo olhar do indígena, seja pelo da sociedade envolvente.

O fio condutor desta análise e observação da cultura Guarani está na produção material de sua arte ainda existente. Acredita-se que o estudo ora apresentado trará contribuição não só para a comunidade acadêmica, mas para a sociedade envolvida.

Os Guarani são dotados de uma cultura particular, são organizados numa sociedade que tem a tradição da família extensa. Alguns se dedicam à arte de produzir sua riqueza material, apesar de algumas interferências externas da comunidade envolvente, como a tinta para as penas e o barbante para substituir o pindó ${ }^{1}$.

Nos últimos anos, os Guaranis da TID vêm lutando pela sobrevivência. Para a reversão da situação dependem da vontade das lideranças e dos produtos originais antes existentes e que hoje não se fazem mais presentes no território, sendo eles obrigados a caminhar muitos quilômetros para conseguir, como o caraguatá ${ }^{2}$. Diante disso, eles têm, também, que enfrentar outras dificuldades, como a necessidade da garantia da subsistência, hoje ainda mais difícil, tendo em vista a diminuição do território pelo aumento populacional e as dificuldades referentes a renda, tanto no trabalho dentro da Terra Indígena quanto no trabalho fora, changa, ainda presente nos dias atuais.

Os Guarani da TID são os que mais lutam pela conservação dos traços culturais tradicionais, assim como para determinar sua forma de sobrevivência. A ideia de tradição é um dos indicativos que são apontados quando procuram conservar suas artes, formas de poder e de representação entre eles. Mesmo sofrendo influências diretas do meio externo, revelam seu apego a um modo de vida apoiado no uso da produção de subsistência, embora em menor proporção.

\section{O processo histórico desta cultura indígena}

A Constituição de 1988 propiciou a discussão da questão cultural indígena, que vem sendo debatida pelos indigenistas, questão importante porque cada sociedade formada em Terras Indígenas (TI) no Brasil toma consciência de sua condição e de

\footnotetext{
${ }^{1}$ Pindó - palmeira que é considerada sagrada pelos Guarani. As folhas desta palmeira são utilizadas na construção de casas e é nativa da Mata Atlântica.

${ }^{2}$ Caraguatá - tem folhas longas com espinhos. As fibras do caraguatá servem para o preparo de roupas, cintos, bolsas e redes.
} 
sua existência e as evidenciam para os Órgãos competentes e para a sociedade circunvizinha.

A cultura pré-determinada por essas comunidades, assim como a necessidade de expor para a comunidade do entorno o sentido de sua identidade, é discutida por Silvio Romero, quando afirma que: "a educação se dá através do processo de imitação, o que possibilita a transmissão da herança cultural por meio de gerações" (ORTIZ 1985, 17).

Observamos que os Ñandeva e os Kayowá passaram por um período de desarticulação, na década de 1970 e 1980, sendo afastados de seus rezadores por uma questão política interna e pela necessidade da changa, pois, no momento do contrato, a eles era imposto um afastamento de seus familiares por 30, 60 ou até 90 dias, o que comprometia a forma de educação na família.

Devemos considerar, também, que o trabalho fora da TID trouxe conhecimento adquirido pelos trabalhadores na sociedade com que passaram a conviver, como é o caso das Feras, que era uma ação de um grupo de homens de mais ou menos 10 pessoas, que soltava uma mulher em meio à lavoura da cana e cada um que conseguisse pegá-la faria sexo.

Isso comprometia, porque algumas famílias se deslocavam inteiras, assim todas as mulheres corriam o risco de serem abordadas. A casa de lona era atacada por estes homens que queriam pelo menos uma das mulheres ali presentes (informações descritas durante as entrevistas).

Quanto à comunidade dos Terena, a situação era um tanto diferente porque eles eram os "gatos", termo utilizado pelo empreiteiro de mão de obra na aldeia.

Sabemos que as comunidades indígenas possuem identidade formada por simbolismos, não deixando dúvidas de que é construída pelas diferenças internas, conforme os diferentes acontecimentos em seu interior, dominado pela relação de poder. A luta pela definição do que seria uma identidade autêntica delimitada pelas fronteiras de uma política que, de uma forma ou de outra, se impõe como legítima, como é o caso das eleições dos capitães nas duas aldeias, a Bororó e a Jaguapiru. Tudo indica que na Bororó os acontecimentos são mais tranquilos e existe um consenso, em alguns momentos, podendo existir uma sequência de membros da mesma família no comando, uns com maior liderança e outros, com menor.

O que não acontece na Jaguapiru, onde a capitania mudava de mão em mão, porém o capitão Ramão Machado, hoje falecido, sempre estava no comando, através dos seus indicados e da sua forma autoritária de exercer o poder. Colocar a problemática dessa forma é afirmar que existe uma identidade e uma cultura em consonância com os interesses dos diferentes grupos sociais que se relacionam internamente, um com maior harmonia e outro com maior poder de decisão, mantendo fatores discriminadores e de exclusão.

Para Miranda, 
a cultura é uma invenção ou, no mínimo uma construção e artefato histórico. $\mathrm{Na}$ sua enunciação, isso implica uma crítica da 'naturalização e da 'substancialização' da cultura. Isso nada diz contra ela, apenas a recoloca contra a mitologia antropológica que considera que o homem produz cultura tão 'naturalmente' como as abelhas produzem o mel ou as aranhas as suas teias (2002, p. 58).

O que não deixa de ser verdade, considerando que o simbólico produz um imaginário principalmente entre os Ñandeva e os Kayowá, tendo em vista que ambos mantêm parte de suas atividades culturais, hoje com maior intensidade, com a tentativa da própria comunidade de formar rezadores, quer dizer, voltando às tradições.

Appadurai diz que:

a cultura não é utilmente encarada como uma substância, sendo melhor vê-la como uma dimensão fenomenal, uma dimensão que trata da diferença situada e incorporada. Dar mais importância à dimensionalidade da cultura do que à sua substancialidade permite-nos pensar a cultura menos como uma propriedade de indivíduos e grupos e mais como um instrumento heurístico que podemos empregar para falar da diferença (1996, p. 12).

Nesse contexto, a sociedade da aldeia Bororó está comprovadamente mais estruturada. Vive um momento único, o que não quer dizer que todos estejam de acordo, principalmente quando registramos a queima de casas de reza, nas décadas de 1970 e 1980. Não se sabe ao certo quem praticou a ação, porém podemos dizer que alguém não está satisfeito, ou por vingança, ou por tentativa de desarticulação através da força.

Todos estes factores não impediram uma unificação metafísica em torno da ideia de cultura, que Gombich faz remontar a Hegel. Vivemos contemporaneamente os avatares desta 'invenção' da cultura. Como 'categorias', cultura e civilização remetem fundamentalmente para a instauração de um espaço onde se jogam todas as oposições, não havendo nenhuma a reter. Mesmo a oposição, fundamental para ambos estes sincretismos, de 'natureza' e 'artifícios' ou 'história', só é antitética neste espaço, e não fora dele. Acima de tudo, é o fundo de verdade dessas oposições que é escamoteado. (MIRANDA: 2002, 63-4). 
As rezas, as danças, as festas comemorativas e os Aty Guasu, que é uma reunião grande, que acontece de tempo em tempo, se fazem presentes sistematicamente. Não deixando de lado que outras comunidades mais tradicionais têm colaborado intensamente com os Guarani-Ñandeva e os Kayowá para que as ações conjuntas, na comunidade interna, viessem a acontecer.

Para Gustavo Bueno (1996, p.16),

a transformação da cultura em 'mito' foi bem analisada, sustenta que a 'cultura' acabou por se tornar num 'ideal prático' que faz do 'Estado Cultural' a forma culminante do Estado, constituindo um 'mito obscurantista', como foi o mito da 'graça' na Idade Média, e o da 'raça' na primeira metade do século XX.

Apesar do paradoxo interno na TID, entre as duas aldeias, a cultura vem novamente para se afirmar como um domínio autônomo e localizado, através de ações simultâneas, apresentando uma totalização de experiências imprescindíveis para o processo de aprendizado.

Neste momento, não se pode deixar de destacar que a ação da escola com o ensino diferenciado tem sido indispensável ao processo, tendo em vista a interlocução estabelecida como metodologia pelos professores, que é a de buscar na comunidade, entre os mais velhos e os rezadores, a experiência de uma comunidade harmoniosa com saber próprio, desenvolvendo uma capacidade para apreender a totalidade, sendo a cultura essa totalidade.

A miscigenação é elemento de destaque, é histórica pelo processo de ocupação na aldeia Jaguapiru, através dos sistemas de educação influenciados na evangelização, da qual temos heranças diretamente ligadas ao processo cultural, que se configuram no simbólico, no ser indígena, o que contribui ainda mais para a marginalização, escravização e exclusão. Assim, é importante ressaltar que as culturas não são estanques, considerando que cada comunidade tem um saber próprio.

Michel Foucault argumenta que:

Os códigos fundamentais de uma cultura - os que regem a sua linguagem, os seus valores, a hierarquia das suas práticas - fixam para cada homem, logo no início do jogo, as ordens empíricas com que terá de haver-se e nas quais se encontrará. No outro extremo do pensamento, teorias científicas ou interpretações de filósofos explicam a existência geral de uma ordem, a que lei geral esta obedece, que princípio pode dela dar conta, e por que razão é essa ordem que é estabelecida e não esta outra. Contudo, entre estas duas regiões tão distante existe um domínio que, apesar de ter, sobretudo um papel de intermediário, não lhes é menos fundamental: é mais confuso, mais obscuro, sem dúvida menos fácil de 
analisar. É aí que uma cultura, desviando-se insensivelmente das ordens empíricas que os seus códigos primários lhe prescrevem, instaurando uma primeira distância em relação a eles, faz-lhes perder a sua transparência inicial, deixa de se deixar atravessar passivamente por eles, desprende-se dos seus poderes imediatos e invisíveis, liberta-se o suficiente para constatar que essas ordens talvez não sejam nem as únicas possíveis nem as melhores; de forma que se encontra perante o facto bruto de que existem, acima das suas ordens espontâneas, coisas que são em si mesmas ordenáveis, que pertencem a certa ordem muda, enfim, que têm ordem. (in: MIRANDA 2002, p. 89).

Apesar da existência do órgão tutelar e o próprio governo, através da Lei 6001, ainda em vigor, falar em aculturação dos povos indígenas, estes não desapareceram em meio à sociedade do entorno. A resposta para essa questão da cultura, a fragmentação da comunidade, seu ir e vir de um espaço a outro não mudou, nem contribuiu para que esquecessem a experiência tradicional mítica de seu povo. Sendo considerado cada um em especial, a fragmentação deveria contribuir para a desagregação, decompondo paulatinamente a estrutura social.

Para Bosi (CNBB, 2000, p. 20), a "raça" implica elementos biológicos, tendo sido tomada como base para diferenças culturais inatas. Esse estudioso discute também supostas diferenciações, colocando que "raciais" são critérios culturais que diferenciam os grupos humanos que estabelecem princípios para as fronteiras étnicas, observando que a diferença estabelecida entre elas é sutil.

Assim, a cultura é a forma atual de reconstituir a unidade, através das experiências dos mais velhos e dos rezadores, articulando a lógica do simbólico, que permanece no imaginário, retratado em certas figuras, concreto ou não.

Para Miranda,

A dominância da cultura tem muito a ver com o 'fim da história' e a transformação mítica do presente, por efeito da estética, da tecnologia, etc. Ao invés, poderíamos dizer que a história nunca começou nem termina, está sempre a começar e a terminar, pois é um efeito do acontecer do acontecimento, enfim, da sua aparição. Cada acto verdadeiramente livre interrompe o existente, divide o tempo em dois, e 'faz história'. Sendo embora a cultura um acontecimento, temos de reconhecer que entre 'acontecimento' e 'cultura' há uma contradição radical. A cultura é o modo actual de controlar o acontecimento. Do ponto de vista crítico dir-se-á mesmo que cultura e acontecimento são antitéticos. (2002, p. 68). 
As igrejas como Deus e Amor também contribuíram em conjunto com o Estado para o processo de enculturação, fazendo uso da língua para a dominação e forçando os indígenas à integração.

É na conscientização que eles poderão crescer em seus significados, pensando a essência de seu povo e consolidando cada comunidade. Nos vários tempos da história, com diversas possibilidades de apreciação, de conhecimento dos espaços, de cultura, de identidade e de alteridade viveram e vivem estes indígenas.

Destacamos que o turismo passou por um processo evolutivo importante no contexto cultural, como fomento significativo de amparo ao desenvolvimento da demanda e das motivações. Segundo Beni (2002, p. 425), a tipologia refere-se:

[...] ao fluxo de turistas nacionais e internacionais que se deslocam centrados na motivação de suas origens étnicas locais e regionais, e também no legado histórico-cultural de sua ascendência comum. Incluem-se aí ainda aqueles que se deslocam com objetivos eminentemente antropológicos para conhecer "in loco" as características étnico-culturais daqueles povos que constituem o interesse de sua observação. (BENI 2002, p. 425).

De acordo com o conceito criado pelo autor, fica evidente que a motivação das pessoas em se deslocar para espaços turísticos com atratividade baseada na etnicidade, possibilita uma experiência turística fundada em inter-relações, seja ela satisfatória ou não, dependendo do olhar de cada visitante.

Os núcleos indígenas Guarani - compostos principalmente de saber valorizado pela sua cultura, pelo direito de ser índio e de falar sua própria língua que é seu legado histórico-cultural, através da tradição e da espiritualidade - agem através da família extensa, com seus antepassados, pais, filhos, netos e bisnetos.

Por serem os indígenas Guarani de relevância cultural, é preciso atentar-se, na TID de Dourados, para um problema que pode surgir, que é a desorganização dos núcleos familiares, passando a existir a família nuclear. Com o desaparecimento da família extensa passa a existir um individualismo que provoca a perda de autenticidade, que pode instalar-se no seio da comunidade, considerando que a população aumentou, tendo também a população flutuante, aquela que vem para a TID apenas para tratamento de saúde no Hospital da Missão Caiuá, permanecendo ali todo o período de tratamento.

Isso descaracteriza muitas vezes a demanda turística, como pode ser observado na fala de Arruti. Muito embora seus estudos não versem a respeito do turismo, sua abordagem trata do lastro que se encontra na classificação dos grupos: 
No caso da população indígena, o exotismo, a alteridade radical, o universo de referências absolutamente estranho, que deve ser traduzido, fazem com que o dilema fique por conta da necessidade de integrar, absorver e eliminar e, sob o signo do romantismo, proteger como núcleo de nacionalidade [...]. (2006, p, 55-6).

Tais questões se refletem diretamente nos agentes envolvidos na atividade turística, como as pessoas que são os atores da representação cultural que, na luta pela sobrevivência, são capazes de descaracterizar sua cultura para captação de recursos financeiros em benefício próprio.

Há também os empresários do setor turístico responsáveis pela comercialização; o poder público que fomenta a atividade em razão da geração de divisas e impostos para o local e a manutenção dos serviços prestados. Ainda, os turistas que são espectadores e buscam experiências diferenciadas; e também, os cientistas que tratam do assunto, principalmente os relacionados aos impactos sociais, culturais e econômicos gerados pela atividade. Para Grünewald:

[...] a questão da autenticidade não merece atenção se, em seu desenvolvimento, qualifica as contradições culturais modernas em autênticas ou falsas. A questão, no entanto, existe na percepção antropológica, inclusive por se fazer presente entre os atores sociais. Se for favorável à perspectiva de que toda experiência cultural é autêntica, isso deve ser examinado através do discurso dos atores sociais concretos, ou seja, pela forma como é percebida por eles... [com relação aos turistas]... isso não significa necessariamente que os turistas estão se perguntando sobre a autenticidade de suas experiências, as quais ao meu ver são sempre autênticas, pois são experiências turísticas, não importando se um elemento cultural foi construído exclusivamente para a encenação em uma arena turística ou se é imemorialmente tradicional e incorporado ao mercado turístico como mais uma atração: importante é que faz parte da experiência. (GRUNEWALD 2001, p. 33-4).

Ainda segundo Grünewald o turismo pode ser pensado por pessoas experientes que não são originais, não mais conseguirão perceber a dinâmica de uma sociedade em termos gerativos, ignorando que, ao defrontar com a experiência turística, as comunidades e sua dinamicidade cultural podem se transformar na gênese de novos padrões e permanecer autênticas, mesmo por meio de mudanças sociais e culturais.

Dentre os questionamentos, aplicado entre os turistas que visitaram a TID e observaram as apresentações, discute-se: Por que os visitantes são motivados pelo turismo cultural? Qual o nível de interesse do turista e o que espera para certos tipos dos produtos turísticos? Qual a percepção do turista sobre as culturas e os produtos culturais?

Responde-se a esses questionamentos levantados sobre a experiência cultural afirmando-se que o turista deseja informações de novas culturas para seu próprio 
conhecimento e interesse, atendendo as suas expectativas, procurando compreender os significados próprios e mitológicos, vistos através da religião. Isso pode acontecer através das histórias contadas ou das danças apresentadas nas atividades, formadas principalmente nos costumes, na gastronomia, no artesanato entre outros fatores representados simbolicamente. A cultura Guarani proporciona diversos tipos de atrações para possibilitar a satisfação do turista. Esses elementos oferecidos durante a pesquisa promoveram a apresentação do modo de vida tradicional em seu dia a dia - isso foi observado durante as entrevistas com as famílias, com as lideranças.

A religiosidade é determinada através da dança e do canto, que são um refletir sobre seu dia. Com um cordão de homens que batem o maracá e um cordão de mulheres que batem a taquara no chão, dentro ou fora da oca. O retorno do cordão onde tanto os homens quanto as mulheres estão firmemente unidos pelas mãos e com os braços bem esticados.

O canto é feito pelo homem relatando o seu dia, e repetido pelas outras pessoas que compõem o grupo. Esse lamento dura horas, e as pernas precisam estar muito firmes para poder resistir ao tempo. Quando se para, por alguns momentos, tomase a chicha, bebida feita do milho moído, e em algumas vezes misturado ao caldo da cana, fermentado por um ou dois dias. Destacamos que esta bebida possui baixo teor alcoólico. É importante dizer que nesta festa tem-se o encontro das famílias extensas, na realidade de um evento que vai noite adentro até que a lua se vai. $\mathrm{Na}$ gastronomia, o milho, a mandioca, o peixe e a caça são a base da alimentação e os mais apreciados.

O artesanato é caracterizado por meio das peças de madeira, cipó, penas coloridas, o timbó, sendo todas as peças com desenhos geométricos determinados por suas formas com linhas retas. $\mathrm{O}$ turista tem interesse ou curiosidade de conhecer o exótico, na TID, mas não contribui para compreender a movimentação turística nos lugares por onde passam em suas visitas. Assim, a atividade turística promove uma experiência diferenciada, mas é direcionada à esfera econômica. $\mathrm{O}$ aspecto cultural é possibilitado quando o intercâmbio de valores se torna uma experiência emocional aos agentes envolvidos pela atração turística, porém, isso não faz parte do objetivo maior.

Destaca-se a contradição na atividade turística relacionada a preocupações distantes e fragmentadas étnica e culturalmente da sua realidade, pois mantém um vínculo com o capital. Moretti diz que:

As transformações, efetivadas pelo capital na produção deste território, que procuram estruturar os elementos que o compõem, modificam as relações pretéritas construídas historicamente pela sociedade local, em um processo de (des)tradicionalização. Este processo destrói relações sociais e relações com a natureza e constrói outras relações. Trata-se, 
portanto, do processo de construção destrutiva. Este processo é central no capitalismo. Através da construção do novo e da destruição do passado é que ocorre o aumento do lucro e o acúmulo de capital. (MORRETI 2001, p. 70).

O turismo colabora para criar e recriar objetivos para que possa continuar a existir e se fortalecer de forma oportuna, em algumas vezes, para todos os envolvidos no processo, em outros momentos, nos níveis e qualidade de vida de alguns.

Por este motivo, são de concordância as considerações de Molina e Rodriguez (2001), ao afirmarem que o planejamento deve reconhecer no turismo sua complexidade, para processá-lo, de modo a priorizar as mudanças que possam alavancar o desenvolvimento. Caso o turismo seja delineado a partir de uma expectativa reducionista como, por exemplo, a partir dos aspectos econômicos, gera instabilidade nas demais dimensões de uma sociedade.

Neste sentido, o território, hoje já considerado tradicional, passa a desencadear poderes simbólicos de múltiplas faces, reforçando a segregação, viabilizando uma dinâmica de convívio ou de ativação de múltiplas identidades. Portanto, o Guarani possui características fechadas, porem dinâmicas, e em alguns momentos, abertas.

\section{Considerações Finais}

Pelo contexto apresentado, pela entrada do turista em terras indígenas através de visitas planejadas pela comunidade e a empresa que faz o deslocamento do turista, ocorrem alguns problemas que provocam o choque cultural.

É importante dizer que as iniciativas, tanto interna quanto externamente das comunidades indígenas, como reuniões na aldeia com a população, que está sempre pronta a discutir e expor seus problemas internos e suas necessidades está aquém das necessidades dessas comunidades e, portanto, a melhor ação a ser implantada é a gestão participativa e comunitária. Em algumas reuniões grandes, chamadas de Atiguaçú, a questão da identidade, da cultura e da terra são pontos que fundamentam o debate. O turismo está planejado, mas o turista não tem os mesmos objetivos que a proposta feita pelo grupo de discussão.

Hoje os grupos que produzem o artesanato veem a importância e a necessidade dos artigos serem originais, como: cipó, capim, sapé, sementes e outros serem coletados no campo ou na mata, para que estejam dentro da cultura herdada. Mas a atividade só seria uma alternativa viável se os próprios sujeitos da ação pudessem fazer parte do planejamento e da organização da atividade, tendo em vista que as melhorias que chegam deveriam estar subordinadas, e devemos, primeiramente, atender as necessidades locais e não as do turista. 
Acredita-se que não existe uma fórmula para proceder ao sucesso esperado diante da prerrogativa de desenvolvimento do turismo em comunidades indígenas, assim, a discussão e o planejamento dos indígenas e liderança passam por apresentar a importância da cultura, da identidade e da alteridade. Porém, reitera-se que esta estratégia seria bem sucedida caso venha a considerar o dinamismo procedente do afloramento das potencialidades destes núcleos, no que diz respeito à sua cultura como subsídio às suas manifestações, repassada de geração a geração, de pais para filhos. É esse o papel dos mais velhos que detêm o saber. Assim temos a memória coletiva com a aquisição e assimilação de novos conhecimentos, já que são fontes de atratividade e saber, o que pode mudar com o tempo, conforme as necessidades da própria comunidade.

Sabe-se que a atividade turística apresenta impactos que merecem atenção quando relacionada ao seu desenvolvimento. O maior estímulo está direcionado ao aspecto econômico, uma vez que o dinheiro advindo dos visitantes gera novos recursos que circulam na economia da TID, transformando em efeito multiplicador, beneficiando até setores que não são considerados turísticos.

Nesse sentido, o desenvolvimento do turismo deve satisfazer às necessidades econômicas, sociais e estéticas, mantendo simultaneamente a integridade cultural e ecológica para que os benefícios positivos possam ser sentidos pela comunidade local, bem como apreciados pelos visitantes.

\section{Referências}

APPADURAI, Arjun. Cultural Dimensions of Globalization. Examines the role of imagination in the cultural development of our shrinking world. In this bold look at the cultural effects of a shrinking world, leading cultural theorist. 1996.

BENI, M. C. Análise estrutural do turismo. São Paulo: SENAC, 2002.

BUENO, Gustavo. E1 Mito de la Cultura. Barcelona: Prensa Ibérica, 1996.

BRASIL. Constituição da República Federativa do Brasil. Brasília: Senado Federal/ Subsecretaria de Edições Técnicas, 1988.

CONFERÊENCIA NACIONAL DOS BISPOS DO BRASIL. 2000.

ESTATUTO DO ÍNDIO. Lei no 6.001, de 19 de dez. de 1973, Art. 158, Cap. II Dos crimes contra o Índio.

FUNASA. CENSO. Levantamento populacional da Terra Indígena de DouradosMS. 2010 
FUNDAÇÃO NACIONAL DO ÍNDIO. Indicadores dos povos indígenas. Dourados-MS, 2010.

GRÜNEWALD, R. de A. Os índios do descobrimento: tradição e turismo. Rio de Janeiro: Contra Capa, 2006.

HAESBAERT, R. Da desterritorialização à multi territorialidade. Anais do IX Encontro Nacional da ANPUR. v.3. Rio de Janeiro: ANPUR, 2001.

MIRANDA, José A. B. de. Teoria da Cultura. Lisboa: Lisboa Codex, 2002.

MOLINA, S.; RODRÍGUEZ, S. Planejamento integral do turismo: um enfoque para a América latina. Trad. Carlos Valero. Bauru: EDUSC, 2001.

MONTEIRO, M. E, B. Levantamento histórico sobre índios Guarani Kaiowá. Rio de Janeiro: Museu do Índio, 2003.

MORETTI, E. C. Pantanal, paraíso visível e real oculto: o espaço local e o global. Rio Claro: UNESP, 2001. Tese (doutorado) - Universidade Estadual Paulista, Rio Claro - SP.

ORTIZ, Renato. Cultura Brasileira e Identidade Nacional. São Paulo: Brasiliense, 1985.

MEHINE, José Carlos Sebe Bom. História Oral. São Paulo: Brasiliense, 1985.

WENCESLAU, M. E. Índio Kayowá: Suicídio pelo Tekohá. São Paulo: USP, 1994. Tese (doutorado) - Universidade de São Paulo, São Paulo. 
CULTURA, TERRITÓRIO E TURISMO 
Endereço para correspondência:

Marina EvaristoWenceslau - jessika.tur@gmail.com Estrada Dourados/Itahum Km 21 - Dourados 79804-970 - Dourados/MS, Brasil Telefone: (67) 421364

230 | Revista Brasileira de Desenvolvimento Regional, Blumenau, 5 (3), P. 209-230, 2017 